\title{
Differences in Basic Life Support Knowledge Between Junior Medical Students and Lay People: Web-Based Questionnaire Study
}

Ludovic Sturny ${ }^{1}$, MSc; Simon Regard ${ }^{1}$, MD, MPH; Robert Larribau ${ }^{1}$, MD; Marc Niquille ${ }^{1}$, MD; Georges Louis Savoldelli ${ }^{2,3}$, MD, MEd; François Sarasin ${ }^{1}$, MD; Eduardo Schiffer ${ }^{2}$, MD; Laurent Suppan ${ }^{1}$, MD

\footnotetext{
${ }^{1}$ Division of Emergency Medicine, Department of Anesthesiology, Clinical Pharmacology, Intensive Care and Emergency Medicine, University of Geneva Hospitals and Faculty of Medicine, Geneva, Switzerland

${ }^{2}$ Division of Anesthesiology, Department of Anesthesiology, Clinical Pharmacology, Intensive Care and Emergency Medicine, University of Geneva Hospitals and Faculty of Medicine, Geneva, Switzerland

${ }^{3}$ Unit of Development and Research in Medical Education, Faculty of Medicine, University of Geneva, Geneva, Switzerland
}

\section{Corresponding Author:}

Laurent Suppan, MD

Division of Emergency Medicine

Department of Anesthesiology, Clinical Pharmacology, Intensive Care and Emergency Medicine

University of Geneva Hospitals and Faculty of Medicine

Rue Gabrielle-Perret-Gentil 4

Geneva, 1211

Switzerland

Phone: 41795532579

Email: laurent.suppan@hcuge.ch

\section{Abstract}

Background: Early cardiopulmonary resuscitation and prompt defibrillation markedly increase the survival rate in the event of out-of-hospital cardiac arrest (OHCA). As future health care professionals, medical students should be trained to efficiently manage an unexpectedly encountered OHCA.

Objective: Our aim was to assess basic life support (BLS) knowledge in junior medical students at the University of Geneva Faculty of Medicine (UGFM) and to compare it with that of the general population.

Methods: Junior UGFM students and lay people who had registered for BLS classes given by a Red Cross-affiliated center were sent invitation links to complete a web-based questionnaire. The primary outcome was the between-group difference in a 10 -question score regarding cardiopulmonary resuscitation knowledge. Secondary outcomes were the differences in the rate of correct answers for each individual question, the level of self-assessed confidence in the ability to perform resuscitation, and a 6-question score, "essential BLS knowledge," which only contains key elements of the chain of survival. Continuous variables were first analyzed using the Student $t$ test, then by multivariable linear regression. Fisher exact test was used for between-groups comparison of binary variables.

Results: The mean score was higher in medical students than in lay people for both the 10-question score (mean 5.8, SD 1.7 vs mean 4.2, SD 1.7; $P<.001$ ) and 6-question score (mean 3.0, SD 1.1 vs mean 2.0, SD 1.0; $P<.001$ ). Participants who were younger or already trained scored consistently better. Although the phone number of the emergency medical dispatch center was well known in both groups (medical students, $75 / 80,94 \%$ vs lay people, $51 / 62,82 \%$; $P=.06$ ), most participants were unable to identify the criteria used to recognize OHCA, and almost none were able to correctly reorganize the BLS sequence. Medical students felt more confident than lay people in their ability to perform resuscitation (mean 4.7, SD 2.2 vs mean 3.1, SD 2.1; $P<.001$ ). Female gender and older age were associated with lower confidence, while participants who had already attended a BLS course prior to taking the questionnaire felt more confident.

Conclusions: Although junior medical students were more knowledgeable than lay people regarding BLS procedures, the proportion of correct answers was low in both groups, and changes in BLS education policy should be considered.

(J Med Internet Res 2021;23(2):e25125) doi: 10.2196/25125 


\section{KEYWORDS}

basic life support; cardiopulmonary resuscitation; medical students; undergraduate medical education; out-of-hospital cardiac arrest; life support; cardiopulmonary; medical education

\section{Introduction}

Basic life support (BLS) maneuvers and use of automated external defibrillators (AED) have been shown to greatly increase the survival rate after out-of-hospital cardiac arrests (OHCA) [1]. Nevertheless, their application rate remains very different from one region to another $[2,3]$.

In Switzerland, most regions lack a systematic BLS training program for the general population, even though more than 8000 OHCA occur every year in the country [4]. In Geneva, BLS was provided in less than $40 \%$ of OHCA cases between 2009 and 2012 [5].

Medical students might unexpectedly encounter OHCA cases outside of the hospital or university environment and might, given their status, be expected to take care of the situation. Many studies carried out in different medical education systems around the world have however concluded that BLS knowledge among health care students is generally limited [6-10].

Since the first BLS training session for medical students of the University of Geneva - Faculty of Medicine (UGFM) only takes place during the second of their 6-year curriculum, our hypothesis was that they might lack critical knowledge regarding BLS prior to this course. These medical students might, however, be unpredictably faced with OHCA and be expected to respond swiftly and adequately given their chosen profession [11]. Our goal was to assess BLS knowledge among these students prior to their first BLS training and to compare it with that of the general population.

\section{Methods}

\section{Study Design}

A cross-sectional, web-based, questionnaire study compliant with the CHERRIES guidelines was carried out between October 2019 and April 2020 [12]. Such studies do not come within the scope of the Swiss Federal Act on Research involving Human Beings [13]. The study protocol was nevertheless submitted to the regional ethics committee, which declared the project "non-objectionable" (Request \#2019-02047).

\section{Online Platform and Survey Development}

An internet platform was developed using the Joomla 3.9 content management system (Open Source Matters, New York, NY). The Community Surveys Pro component version 5 (CoreJoomla, Hyderabad, India) was used to create the questionnaire.

A structured online questionnaire containing 19 questions requiring either open or closed answers was created on the platform (Multimedia Appendix 1). The number of questions was kept below 20 to limit dropout attrition [14-16]. Ten questions were used to assess BLS knowledge. These questions were prepared according to the 2015 International Consensus on Cardiopulmonary Resuscitation and Emergency Cardiovascular Care Science With Treatment Recommendations [17]. The questionnaire was displayed over a total of 4 pages (Table 1). Both the internet platform and the questionnaire were thoroughly tested for usability and user-friendliness by all coauthors before beginning the study. 
Table 1. Survey structure and questions.

\begin{tabular}{|c|c|}
\hline Survey page and field, Question & Type of question \\
\hline \multicolumn{2}{|l|}{ Introduction: consent } \\
\hline $\mathrm{N} / \mathrm{A}^{\mathrm{a}}$ & N/A \\
\hline \multicolumn{2}{|l|}{ 1: demographics } \\
\hline Year of birth & Open $\left(\operatorname{Regex}^{\mathrm{b}}\right)$ \\
\hline Gender & $\mathrm{MCQ}^{\mathrm{c}}$ \\
\hline \multicolumn{2}{|l|}{ 2: general BLS ${ }^{d}$ knowledge } \\
\hline Ever heard of BLS or ACLS ${ }^{\mathrm{e}}$ before & Yes/No \\
\hline Meaning of “AED”,f,g & Open \\
\hline Year of the last BLS guidelines update & Open (Regex) \\
\hline Phone number of the emergency medical services dispatch center ${ }^{\mathrm{g}, \mathrm{h}}$ & Open \\
\hline \multicolumn{2}{|l|}{ 3: prior BLS experience } \\
\hline $\begin{array}{l}\text { Current or past student of a health care profession, BLS instructor, or professional } \\
\text { rescuer }\end{array}$ & MAQ $^{\mathrm{i}}$ \\
\hline Prior BLS training & Yes/No \\
\hline Wish to be trained, or more trained, in BLS procedures & Yes/No \\
\hline \multicolumn{2}{|l|}{ 4: specific BLS knowledge } \\
\hline Criteria used to recognize $\mathrm{OHCA}^{\mathrm{g}, \mathrm{h}, \mathrm{j}}$ & MAQ \\
\hline BLS sequence $\mathrm{g}^{\mathrm{g}, \mathrm{h}}$ & Ordering \\
\hline Artery for pulse assessment ${ }^{\mathrm{g}}$ & MCQ \\
\hline Compression depth ${ }^{\mathrm{g}, \mathrm{h}}$ & MCQ \\
\hline Compression:ventilation ratio ${ }^{\mathrm{g}}$ & MCQ \\
\hline Compression rate ${ }^{\mathrm{g}, \mathrm{h}}$ & MCQ \\
\hline Compression-only $\mathrm{CPR}^{\mathrm{g}, \mathrm{h}, \mathrm{k}}$ & Yes/No \\
\hline Treatment of a choking patient, conscious, unable to either cough or talk ${ }^{\mathrm{g}}$ & MCQ \\
\hline Self-assessed confidence in the ability to perform resuscitation & $1-10$ scale \\
\hline
\end{tabular}

${ }^{\mathrm{a}} \mathrm{N} / \mathrm{A}$ : not applicable.

${ }^{\mathrm{b}}$ Regex: regular expression validation.

${ }^{\mathrm{c}} \mathrm{MCQ}$ : multiple choice question (only one answer accepted).

${ }^{\mathrm{d}}$ BLS: basic life support.

${ }^{\mathrm{e}} \mathrm{ACLS}$ : advanced cardiovascular life support.

${ }^{f}$ AED: automated external defibrillator.

${ }^{\mathrm{g}}$ Questions used to compute the primary outcome (score out of 10 questions).

${ }^{\mathrm{h}}$ Questions used to compute the "essential BLS knowledge" secondary outcome.

${ }^{\mathrm{i}} \mathrm{MAQ}$ : multiple answer question (more than one answer accepted).

${ }^{j}$ OHCA: out-of-hospital cardiac arrest.

${ }^{\mathrm{k}} \mathrm{CPR}$ : cardiopulmonary resuscitation.

\section{Enrollment and Consent}

As the UGFM BLS-AED course is based on a "flipped classroom" teaching format, medical students must complete an institutional, interactive, electronic learning (eLearning) module prior to attending their first 2-hour BLS-AED workshop. A link was therefore embedded in the very first slide of the
eLearning module (Figure 1), prompting the 183 second-year UGFM students, which represented a convenience sample, to participate in the study before accessing the learning material.

The control group was composed of lay people attending a first aid course. These participants were recruited thanks to the Association Genevoise des Sections de Samaritains (AGSS), a 
Red Cross-affiliated training center. The AGSS agreed to send a single mailing (Multimedia Appendix 2) on our behalf to each first aid course participant who registered between October 2019 and April 2020. In Switzerland, first aid courses are mandatory to obtain a driving license [18]. Though anonymity was ensured by virtue of the invitation method, no reminder could be sent as we did not have access to the participants' email addresses or to their identities. These invitation emails were sent at least 2 weeks before these courses were scheduled, and participants were specifically asked to take the questionnaire before attending the course.
Information regarding the study was displayed along with an electronic consent form before the questionnaire could be started [19]. Participants were informed of the study's purpose and of its estimated length. Identity and contact of the investigators were given, and information regarding data handling was provided. Participants were informed that no personal data would be asked for or recorded and that they would not be solicited any further after having completed the questionnaire.

No incentive was given to promote participation, which was not required to attend either course.

Figure 1. Electronic learning (eLearning) slide inviting medical students to participate in the study.

\title{
Etude sur les connaissances en réanimation
}

\author{
Dans le cadre d'un travail de master, nous cherchons à évaluer les \\ connaissances des étudiants en médecine en 2 ème année avant la \\ formation en réanimation proposée dans le cadre des séminaires de \\ competences cliniques.
}
A cet effet, nous vous serions reconnaissants de participer à notre étude en cliquant sur le bouton ci-dessous. Cela ne devrait pas vous prendre plus de 10 minutes (et probablement meme moins de 5 minutes).
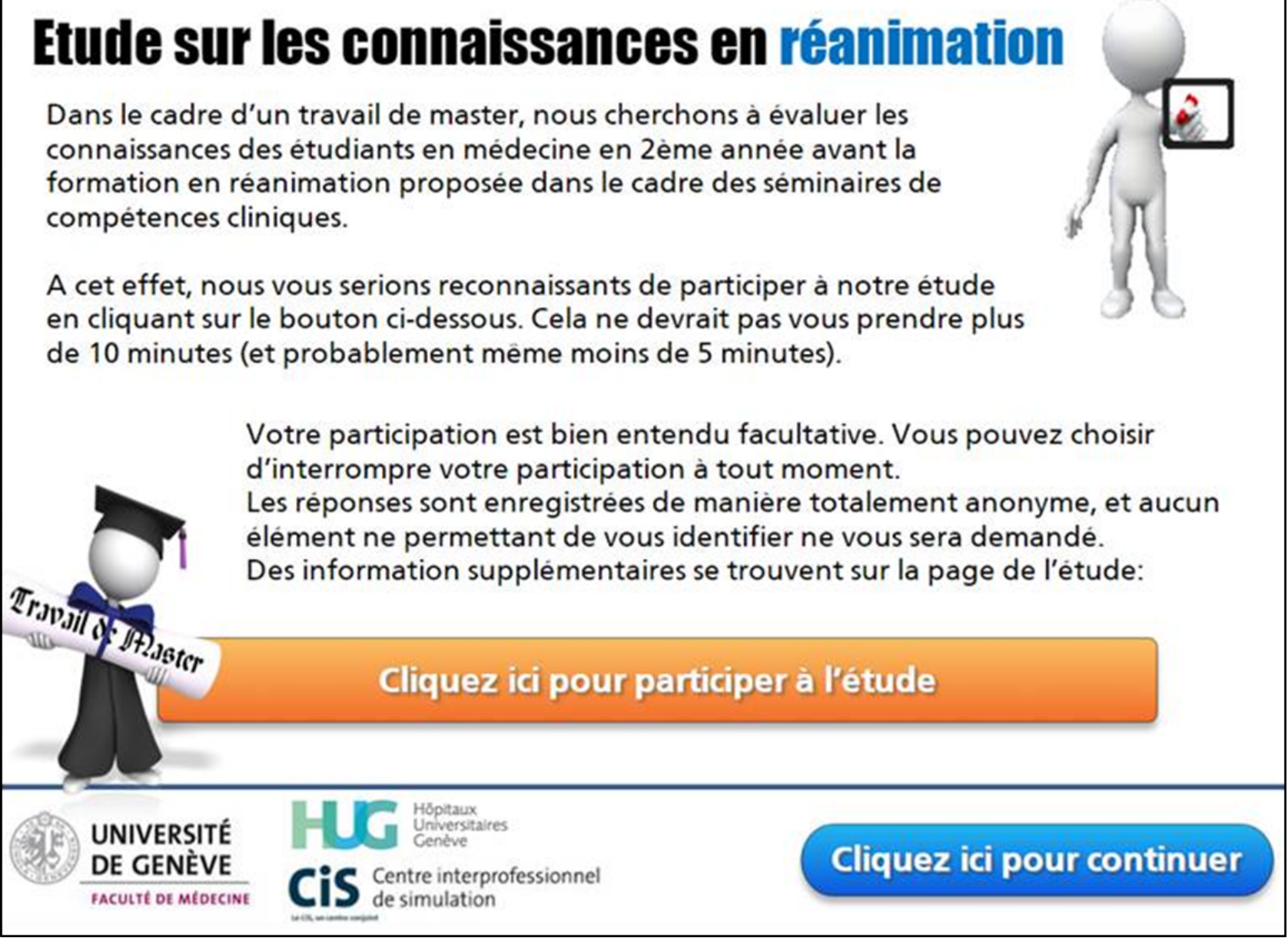

\section{Data Collection}

All questions had to be answered, and pages were to be entirely filled before participants could proceed to the following part of the survey. Answer consistency was checked using regular expression (regex) validation rules, and participants were warned whenever an inconsistent answer was identified. Participants could change their answers using a "back" button until the questionnaire was finalized.

Data were stored on an encrypted MySQL compatible database (MariaDB 5.5.5, MariaDB Foundation, Wakefield, MA) located on a Swiss server. As this was a closed survey, with the link only provided either on the first eLearning slide or in the emails sent by the AGSS, no specific tracking identifier (cookies or IP address) was used.

\section{Outcomes}

The primary outcome was the between-group difference on the 10 -question quiz score. Each question was equally weighted and could only be considered as correct or incorrect. Thus, the total score was computed for each participant by summing all correct answers. Secondary outcomes were the differences in the rate of correct answers for each individual question and in the level of self-assessed confidence in the ability to perform resuscitation. We also computed a score dubbed "essential BLS knowledge," which is the sum of 6 critical questions related to BLS (Table 1) and follows the logic of the chain of survival. Indeed, the other questions used to compute the primary outcome are either related to other first aid maneuvers or are not deemed of critical importance to the adequate provision of resuscitative maneuvers. 


\section{Data Availability}

The original data have been deposited to Mendeley Data [20].

\section{Statistical Analysis}

Statistical analysis was carried out using STATA 16.1 (StataCorp LLC, College Station, TX). Incomplete questionnaires, as well as those completed by BLS-AED instructors or already certified health care professionals, were excluded from the analysis.

The scores of the answers to the 10 predefined questions were added to compute the overall quiz score defined as the primary outcome $($ minimum $=0$; maximum $=10)$. No differential weighting was applied, and each individual question was worth 1 point. The "essential BLS knowledge" score was computed in the exact same way (minimum $=0$; maximum $=6$ ).

Normality was assessed both graphically and by the Kolmogorov-Smirnov test. Analysis of continuous variables was first performed using the Student $t$ test, and results were then adjusted according to age, gender, and prior BLS experience through the use of multivariable linear regression. Results are presented as mean (SD). Given the limited sample size, the Fisher exact test was used for between-groups comparison of binary variables. A double-sided $P$ value $<.05$ was considered significant.

A subgroup analysis to identify a potential effect of having attended a BLS course prior to taking the survey was decided post hoc. A sensitivity analysis excluding medical students who had prior training as health care students or who were already certified rescuers was also performed.

\section{Results}

The participation rate was higher $(P=.03)$ in the medical students' group $(80 / 183,44 \%)$ than in the control group $(74 / 256$, $29 \%$ ). While no participant had to be excluded from the medical students' group, the exclusion criteria were met for 12 participants in the control group (Figure 2). Among the 80 medical students who completed the survey, 1 was a former nursing student, and 13 answered they were certified rescuers. There were no fully qualified health care professionals in this group.

Participants were older in the control group (mean 34.0 years, SD 12.7 years) than in the medical students' group (mean 22.5 years, SD 4.4 years). There was a majority of women in both groups $(49 / 74,66 \%$ in the control group and 58/80, $73 \%$ in the medical students' group) with no significant difference between groups $(P=.35)$. While the proportion of participants who had already heard of BLS or of advanced cardiovascular life support was also similar (48/80, $60 \%$ of medical students vs $41 / 74,55 \%$ of lay people; $P=.39$ ), medical students more often declared having already attended a BLS course $(68 / 80,85 \%$ vs $45 / 74$, $61 \%, P<.001)$.

The mean score on the 10-question composite outcome was higher in medical students (mean 5.8, SD 1.7 vs mean 4.2, SD $1.7 ; P<.001$ ), with 6 questions displaying significant differences (Table 2). Older participants were more likely to score lower, with a coefficient of -0.031 per year ( $95 \% \mathrm{CI}-0.060$ to -0.003 , $P=.03$ ), while the participants who had attended a BLS course prior to taking the questionnaire scored higher $(1.166,95 \% \mathrm{CI}$ 0.470 to $1.862, P=.001)$. No participant was able to correctly answer all 10 questions.

Medical students also scored better than lay people on the 6-question "essential BLS knowledge" score (mean 3.0, SD 1.1 vs mean 2.0 , SD $1.0 ; P<.001)$. Older age was also correlated with lower scores (coefficient -0.025 per year, $95 \%$ CI -0.043 to $-0.007, P=.007$ ), and participants who had attended a BLS course prior to completing the questionnaire also scored higher on this index $(0.698,95 \%$ CI 0.258 to $1.138, P=.002)$. Once again, no participant was able to correctly answer all 6 questions. Neither score was affected by gender.

Lay people who had already attended a BLS course before participating in the survey did not perform better than those who had not (mean 4.5, SD 1.6 vs mean 3.8, SD 1.7, $P=.14$ ). The same held true for medical students (mean 5.9, SD 2.2 vs mean 5.4, SD 1.6, $P=.39$ ).

Medical students felt more confident than lay people in their ability to perform resuscitation (mean 4.7, SD 2.2 vs mean 3.1, SD 2.1, $P<.001$ ). Participants who had already attended a BLS course felt more confident than those who had not (coefficient $1.9,95 \%$ CI 1.1 to $2.7, P<.001$ ), while female participants felt less confident (coefficient $-1.1,95 \% \mathrm{CI}-1.9$ to $-0.4, P=.003$ ). Older participants felt less confident than their younger counterparts (coefficient -0.041 per year, $95 \%$ CI -0.074 to $-0.009, P=.01$ ). The proportion of participants wishing to receive more BLS training was higher in the group composed of medical students $(70 / 80,88 \%$ vs $42 / 74,57 \%, P<.001)$.

Excluding medical students who were either former nursing students or certified rescuers neutralized the effect of age on the 10-question score and on the confidence but did not significantly change the magnitude or direction of the other results. 
Figure 2. Study flowchart for (A) lay people and (B) medical students. AED: automated external defibrillator; BLS: basic life support.
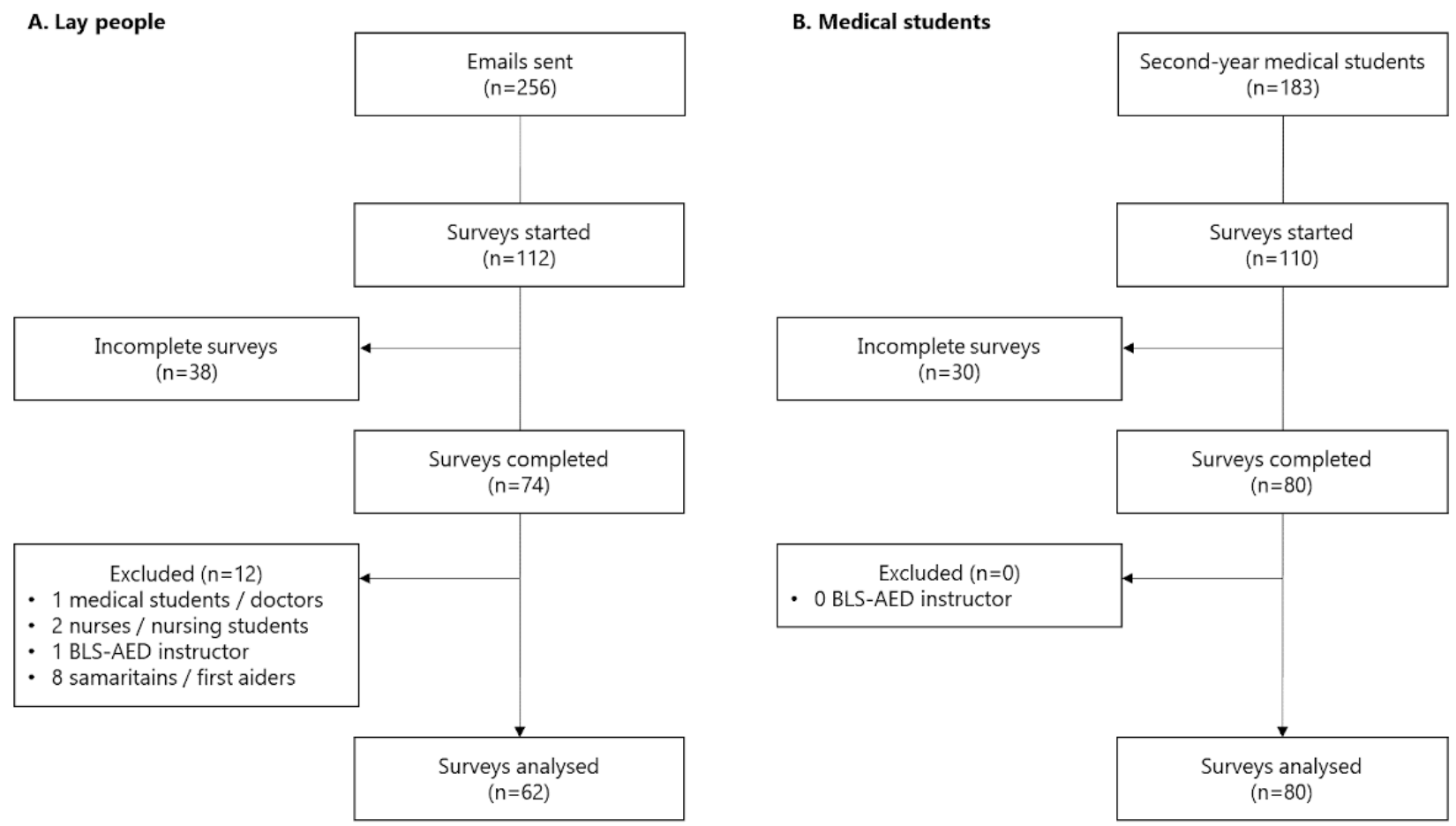

Table 2. Scores on the 10-question composite outcome by group.

\begin{tabular}{|c|c|c|c|}
\hline Question & Lay people $(\mathrm{n}=62), \mathrm{n}(\%)$ & Medical students $(\mathrm{n}=80), \mathrm{n}(\%)$ & $P$ value \\
\hline Phone number of the emergency medical services dispatch central ${ }^{\text {a }}$ & $51(82)$ & $75(94)$ & .06 \\
\hline Meaning of "AED”, & $27(44)$ & $42(53)$ & .31 \\
\hline Criteria used to recognize $\mathrm{OHCA}^{\mathrm{d}}$ & $5(8)$ & $16(20)$ & .06 \\
\hline BLS $^{\mathrm{e}}$ sequence & $2(3)$ & $0(0)$ & .19 \\
\hline Artery for pulse assessment & $50(80)$ & $50(63)$ & .03 \\
\hline Compression depth & $9(14)$ & $29(36)$ & .004 \\
\hline Compression:ventilation ratio & $21(34)$ & $62(78)$ & $<.001$ \\
\hline Compression rate & $15(24)$ & $41(51)$ & .002 \\
\hline Compression-only CPR ${ }^{\mathrm{f}}$ & $39(63)$ & $75(94)$ & $<.001$ \\
\hline Treatment of a choking patient, conscious, unable to either cough or talk & $43(69)$ & $75(94)$ & $<.001$ \\
\hline
\end{tabular}

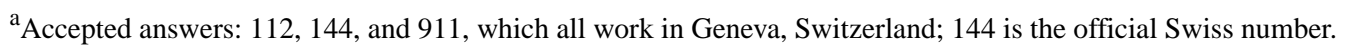

bAED: automated external defibrillator.

"All answers containing "defibrillator" in English or in French were considered as correct (not case sensitive, spelling mistakes accepted).

${ }^{\mathrm{d}} \mathrm{OHCA}$ : out-of-hospital cardiac arrest.

${ }^{\mathrm{e}}$ BLS: basic life support.

${ }^{\mathrm{f}} \mathrm{CPR}$ : cardiopulmonary resuscitation.

\section{Discussion}

\section{Principal Findings}

In this study, second-year medical students performed somewhat better than lay people, though neither group scored high on a simple 10-question quiz assessing BLS knowledge. The difference might arise from different grounds. First of all, medical students might indeed be more interested in this domain given their chosen profession. Moreover, though our regional policies have evolved little with regard to BLS training promotion, private initiatives have progressively surfaced in an attempt to increase general awareness regarding OHCA. As medical students were more than a decade younger than the 
control group, they might have been more exposed to such campaigns and therefore more interested in this topic.

Our findings highlight weaknesses in the first 3 links of the chain of survival [21]. While the proportion of participants who correctly remembered the phone number of the medical emergency communication center was high in both groups, most were unable to correctly describe the criteria used to identify OHCA. Failure to correctly identify OHCA may lead to a delayed call to the dispatch center and thereby worsen the victim's prognosis [22]. Once called, dispatchers should nevertheless be able to help identify OHCA and lead the bystander to start appropriate actions [23]. However, while cardiopulmonary resuscitation (CPR) might be initiated, our survey results suggest that compression could be of limited quality since answers related to compression rate and depth were mostly incorrect. These findings are worrying since high-quality chest compressions are of paramount importance and have been shown to improve survival outcomes [24-26]. The third link in the chain, defibrillation, was only assessed with one simple question that focused on the meaning of the AED abbreviation. Less than half of all participants were able to determine that these 3 letters were commonly used to refer to a defibrillator. However, one could reasonably expect that associating the lightning pictograph to the abbreviation might improve identification of these devices [27]. Moreover, most emergency medical dispatchers are now trained to help bystanders or first responders localize, retrieve, and use AEDs [28].

Although lay rescuers, either trained or untrained, have not been expected to check for a pulse since the publication of the 2010 CPR guidelines [29], we nevertheless elected to ask a question regarding pulse assessment. Indeed, our BLS teaching faculty considers even junior medical students to be health care providers, and these students are therefore expected to know how to check for a pulse, particularly to assess a potential return of spontaneous circulation [30]. It must however be unequivocal that the pulse check should not be performed to diagnose cardiac arrest as it has been shown to be highly unreliable [31].

Even though emergency medical systems have evolved to overcome as much as possible the lack of BLS training [32], developing first aid knowledge and skills among the general population is essential to improve outcomes not only in OHCA victims but also in patients presenting with other acute illnesses or injuries [33]. Many different strategies can be considered to enhance the global level of awareness regarding OHCA and CPR, including systematic teaching of BLS maneuvers to school children [34-36]. This strategy has been shown to be particularly effective, as children are eager to transfer their acquired knowledge to their parents, siblings, and friends [37,38]. Training school children and providing them with cheap, basic manikins has been shown to help disseminate CPR training among their relatives [39], and many European countries have adhered to the "KIDS SAVE LIVES" statement, which aims to provide BLS education to schoolchildren aged 12 years and older [40]. Until such a change in BLS education policies occurs, medical students should be offered first aid courses earlier in their curriculum. The recently released European Resuscitation Council guidance note related to the CPR competencies required in undergraduate health care students could be used as a guideline to facilitate the implementation of BLS courses sooner in the undergraduate curriculum [41]. This note advocates, as we do, for the mandatory teaching of BLS maneuvers already during the first year of undergraduate education for students of health care professions.

However, months, if not years, might elapse before any change in public health policies can be accomplished, and modifying the undergraduate medical curriculum might take just as long. Therefore, to enhance the awareness of UGFM junior medical students regarding BLS issues, a team of senior medical students and faculty members developed an accelerated first aid course [42]. In January 2021, first-year medical students attended a brief intervention inviting them to complete an eLearning module. In the context of the current COVID-19 pandemic, asynchronous distance learning using interactive eLearning modules has been shown to enhance knowledge acquisition in medical students [43]. After completing this module, first-year medical students were invited to register for 1-hour practice sessions. Students who successfully complete this learning path will be able to enlist as first responders. Future studies should determine whether this strategy is successful and can improve BLS knowledge in this population.

The results of our post hoc analysis regarding the effect of having attended a BLS course prior to taking the survey are cause for concern. Indeed, participants who declared having attended such a course in the past did not perform significantly better than those who did not, regardless of the study group. While a change in the guidelines between a prior course and the moment of the survey could be hypothesized, the young age of the participants, particularly in the medical students' group, makes it unlikely. Low scores were indeed recorded regarding key elements that were already part of the 2010 guidelines (ie, the criteria used to recognize OHCA [29]). Many factors, such as the time elapsed since the last BLS course, the course format, or the number of previous courses the participants had attended, may explain the apparent lack of BLS knowledge retention [44-46]. However, as this was an unexpected finding, the design of our study was ill suited to explore its grounds, and further studies will be needed to confirm this result and try to determine potential causes.

This study has other limitations that should also be acknowledged. First, owing to the study design and to the impossibility of sending email reminders, the participation rate was rather low, particularly among lay rescuers. This might have led to an overestimation of BLS knowledge in both groups due to selection bias. The method of recruitment has been shown to significantly alter the participation rates $[47,48]$, and previous studies have reported that paper questionnaires have slightly higher response rates than web-based ones [49]. The use of paper questionnaires is however associated with much higher costs and carries an increased risk of generating missing values.

In addition, we were unable to determine whether the questionnaire had actually been completed before the course. Nevertheless, medical students were required to complete the eLearning module with the embedded invitation slide before 
attending their first BLS course, and lay people were sent the invitation email at least 2 weeks before attending their course.

Another limitation is that our control group cannot be considered as a true surrogate of the general population. Indeed, as participants were rather young and as BLS training initiatives have progressively increased, it is to be expected that BLS knowledge would actually be lower in a more representative sample of the general population. Another limitation is linked to the specificities of the UGFM curriculum. In our curriculum, medical students and dental medicine students share a common study path until the end of their second year of undergraduate training. Around one-fifth of second-year UGFM students are actually dental medicine students. There is however little reason to believe that their interest in BLS procedures should be different for these students compared to medical students whose interest is not in an acute medicine specialty. In addition, most junior medical students have not yet decided upon a specific career at this stage [50]. One last limitation is that no survey can be considered as a true assessment of the way bystanders would manage OHCA. Nevertheless, there is a correlation between confidence, CPR skills, and intention to perform resuscitation, and a low level of knowledge can hardly foster confidence [51].

\section{Conclusion}

Although medical students were more knowledgeable than lay people regarding BLS-AED procedures, their proportion of correct answers was still low. As OHCA recognition and high-quality chest compressions are paramount to increasing survival rates, a change in the curriculum, as well as a global transformation in the way the general population is educated regarding first aid maneuvers, could help improve outcomes.

\section{Acknowledgments}

The authors would like to thank the Association Genevoise des Sections de Samaritains (AGSS) and particularly Mrs Véronique Volken for having dispatched invitation emails on their behalf.

\section{Conflicts of Interest}

None declared.

\section{Multimedia Appendix 1}

Questions and expected answers: original (French) version and English translation.

[PDF File (Adobe PDF File), 470 KB-Multimedia Appendix 1]

\section{Multimedia Appendix 2}

Text sent in the invitation e-mails (dispatched on our behalf by the Association Genevoise des Sections de Samaritains). [PDF File (Adobe PDF File), 50 KB-Multimedia Appendix 2]

\section{References}

1. Kiyohara K, Sado J, Kitamura T, Ayusawa M, Nitta M, Iwami T, et al. Public-access automated external defibrillation and bystander-initiated cardiopulmonary resuscitation in schools: a nationwide investigation in Japan. Europace 2019 Mar 01;21(3):451-458. [doi: 10.1093/europace/euy261] [Medline: 30500911]

2. Rivera NT, Kumar SL, Bhandari RK, Kumar SD. Disparities in Survival with Bystander CPR following Cardiopulmonary Arrest Based on Neighborhood Characteristics. Emerg Med Int 2016;2016:6983750-6983758 [FREE Full text] [doi: 10.1155/2016/6983750] [Medline: 27379186]

3. Bray JE, Straney L, Smith K, Cartledge S, Case R, Bernard S, et al. Regions With Low Rates of Bystander Cardiopulmonary Resuscitation (CPR) Have Lower Rates of CPR Training in Victoria, Australia. JAHA 2017 Nov 06;6(6):1. [doi: 10.1161/jaha.117.005972] [Medline: 28584073]

4. Wietlisbach M, Schüpfer G. [Resuscitation]. Praxis (Bern 1994) 1997 Feb 04;86(6):182-188. [Medline: 9082524]

5. Larribau R, Deham H, Niquille M, Sarasin FP. Improvement of out-of-hospital cardiac arrest survival rate after implementation of the 2010 resuscitation guidelines. PLoS One 2018 Sep 24;13(9):e0204169 [FREE Full text] [doi: 10.1371/journal.pone.0204169] [Medline: $\underline{30248116]}$

6. Baldi E, Contri E, Bailoni A, Rendic K, Turcan V, Donchev N, et al. Final-year medical students' knowledge of cardiac arrest and CPR: We must do more!. Int J Cardiol 2019 Dec 01;296:76-80. [doi: 10.1016/j.ijcard.2019.07.016] [Medline: $\underline{31375334]}$

7. Roshana S, Kh B, Rm P, Mw S. Basic life support: knowledge and attitude of medical/paramedical professionals. World J Emerg Med 2012;3(2):141-145 [FREE Full text] [doi: 10.5847/wjem.j.issn.1920-8642.2012.02.011] [Medline: 25215053]

8. Kila T, Yockopua S. Knowledge of cardiopulmonary resuscitation among doctors at the Port Moresby General Hospital. P N G Med J 2012;55(1-4):76-87. [Medline: 25338477]

9. Almesned A, Almeman A, Alakhtar AM, AlAboudi AA, Alotaibi AZ, Al-Ghasham YA, et al. Basic life support knowledge of healthcare students and professionals in the Qassim University. Int J Health Sci (Qassim) 2014 Apr;8(2):141-150 [FREE Full text] [doi: 10.12816/0006080] [Medline: 25246881] 
10. Willmore RD, Veljanoski D, Ozdes F, Stephens B, Mooney J, Crumley SG, et al. Do medical students studying in the United Kingdom have an adequate factual knowledge of basic life support? World J Emerg Med 2019;10(2):75-80 [FREE Full text] [doi: $10.5847 /$ wjem.j.1920-8642.2019.02.002] [Medline: $\underline{30687442}$ ]

11. Xie JY, Frost R, Meakin R. Not quite a doctor, but should I help? A qualitative exploration of medical students' attitudes towards responding to medical emergencies that occur in the public domain. BMJ Open 2019 Apr 08;9(4):e028035 [FREE Full text] [doi: 10.1136/bmjopen-2018-028035] [Medline: 30962243]

12. Eysenbach G. Improving the quality of Web surveys: the Checklist for Reporting Results of Internet E-Surveys (CHERRIES). J Med Internet Res 2004 Sep 29;6(3):e34 [FREE Full text] [doi: 10.2196/jmir.6.3.e34] [Medline: 15471760]

13. SR 810.30 Federal Act of 30 September 2011 on Research involving Human Beings (Human Research Act, HRA). Swiss Confederation. 2011. URL: https://www.admin.ch/opc/en/classified-compilation/20061313/index.html [accessed 2020-05-12]

14. McCambridge J, Kalaitzaki E, White IR, Khadjesari Z, Murray E, Linke S, et al. Impact of length or relevance of questionnaires on attrition in online trials: randomized controlled trial. J Med Internet Res 2011 Nov 18;13(4):e96 [FREE Full text] [doi: 10.2196/jmir.1733] [Medline: 22100793]

15. Eysenbach G. The law of attrition. J Med Internet Res 2005 Mar 31;7(1):e11 [FREE Full text] [doi: 10.2196/jmir.7.1.e11] [Medline: 15829473$]$

16. Hochheimer CJ, Sabo RT, Perera RA, Mukhopadhyay N, Krist AH. Identifying Attrition Phases in Survey Data: Applicability and Assessment Study. J Med Internet Res 2019 Aug 23;21(8):e12811 [FREE Full text] [doi: 10.2196/12811] [Medline: 31444875]

17. Travers AH, Perkins GD, Berg R, Castren M, Considine J, Escalante R, Basic Life Support Chapter Collaborators. Part 3: Adult Basic Life Support and Automated External Defibrillation: 2015 International Consensus on Cardiopulmonary Resuscitation and Emergency Cardiovascular Care Science With Treatment Recommendations. Circulation 2015 Oct 20;132(16 Suppl 1):S51-S83. [doi: 10.1161/CIR.0000000000000272] [Medline: 26472859]

18. Regard S, Rosa D, Suppan M, Giangaspero C, Larribau R, Niquille M, et al. Evolution of Bystander Intention to Perform Resuscitation Since Last Training: Web-Based Survey. JMIR Form Res 2020 Nov 30;4(11):e24798 [FREE Full text] [doi: 10.2196/24798] [Medline: 33252342]

19. Eysenbach G, Wyatt J. Using the Internet for surveys and health research. J Med Internet Res 2002 Nov;4(2):E13 [FREE Full text] [doi: 10.2196/jmir.4.2.e13] [Medline: 12554560]

20. Sturny L, Regard S, Schiffer E, Suppan L. Basic life support knowledge among junior medical students dataset. Mendeley Data 2020:1. [doi: 10.17632/99w7bb2p5v.1]

21. Perkins GD, Handley AJ, Koster RW, Castrén M, Smyth MA, Olasveengen T, Adult basic life support and automated external defibrillation section Collaborators. European Resuscitation Council Guidelines for Resuscitation 2015: Section 2. Adult basic life support and automated external defibrillation. Resuscitation 2015 Oct;95(10):81-99. [doi:

10.1016/j.resuscitation.2015.07.015] [Medline: 26477420]

22. Waalewijn RA, Tijssen JG, Koster RW. Bystander initiated actions in out-of-hospital cardiopulmonary resuscitation: results from the Amsterdam Resuscitation Study (ARRESUST). Resuscitation 2001 Sep;50(3):273-279. [doi: 10.1016/S0300-9572(01)00354-9] [Medline: 11719156]

23. Vaillancourt C, Verma A, Trickett J, Crete D, Beaudoin T, Nesbitt L, et al. Evaluating the effectiveness of dispatch-assisted cardiopulmonary resuscitation instructions. Acad Emerg Med 2007 Oct;14(10):877-883 [FREE Full text] [doi: 10.1197/j.aem.2007.06.021] [Medline: 17761545]

24. Stiell IG, Brown SP, Christenson J, Cheskes S, Nichol G, Powell J, Resuscitation Outcomes Consortium (ROC) Investigators. What is the role of chest compression depth during out-of-hospital cardiac arrest resuscitation? Crit Care Med 2012 Apr;40(4):1192-1198 [FREE Full text] [doi: 10.1097/CCM.0b013e31823bc8bb] [Medline: 22202708]

25. Vadeboncoeur T, Stolz U, Panchal A, Silver A, Venuti M, Tobin J, et al. Chest compression depth and survival in out-of-hospital cardiac arrest. Resuscitation 2014 Feb;85(2):182-188. [doi: 10.1016/j.resuscitation.2013.10.002] [Medline: 24125742]

26. Idris AH, Guffey D, Pepe PE, Brown SP, Brooks SC, Callaway CW, et al. Chest Compression Rates and Survival Following Out-of-Hospital Cardiac Arrest*. Critical Care Medicine 2015;43(4):840-848. [doi: 10.1097/ccm.0000000000000824] [Medline: 25565457]

27. Smith CM, Colquhoun MC, Samuels M, Hodson M, Mitchell S, O'Sullivan J. New signs to encourage the use of Automated External Defibrillators by the lay public. Resuscitation 2017 May;114:100-105. [doi: 10.1016/j.resuscitation.2017.03.012] [Medline: 28323083]

28. Stieglis R, Zijlstra JA, Riedijk F, Smeekes M, van der Worp WE, Koster RW. AED and text message responders density in residential areas for rapid response in out-of-hospital cardiac arrest. Resuscitation 2020 May;150:170-177 [FREE Full text] [doi: 10.1016/j.resuscitation.2020.01.031] [Medline: 32045663]

29. Koster RW, Baubin MA, Bossaert LL, Caballero A, Cassan P, Castrén M, et al. European Resuscitation Council Guidelines for Resuscitation 2010 Section 2. Adult basic life support and use of automated external defibrillators. Resuscitation 2010 Oct;81(10):1277-1292 [FREE Full text] [doi: 10.1016/j.resuscitation.2010.08.009] [Medline: 20956051]

30. Moule P. Checking the carotid pulse: diagnostic accuracy in students of the healthcare professions. Resuscitation 2000 May;44(3):195-201. [doi: 10.1016/s0300-9572(00)00139-8] [Medline: 10825620] 
31. Ochoa F, Ramalle-Gómara E, Carpintero J, Garcı'a A, Saralegui I. Competence of health professionals to check the carotid pulse. Resuscitation 1998 Jun;37(3):173-175. [doi: 10.1016/s0300-9572(98)00055-0] [Medline: 9715777]

32. Tanaka Y, Taniguchi J, Wato Y, Yoshida Y, Inaba H. The continuous quality improvement project for telephone-assisted instruction of cardiopulmonary resuscitation increased the incidence of bystander CPR and improved the outcomes of out-of-hospital cardiac arrests. Resuscitation 2012 Oct;83(10):1235-1241. [doi: 10.1016/j.resuscitation.2012.02.013] [Medline: 22366353]

33. Zideman DA, De Buck ED, Singletary EM, Cassan P, Chalkias AF, Evans TR, et al. European Resuscitation Council Guidelines for Resuscitation 2015 Section 9. First aid. Resuscitation 2015 Oct;95:278-287. [doi: 10.1016/j.resuscitation.2015.07.031] [Medline: 26477417]

34. Baznik S, Mohar A. Basic life support training for primary school children. Resuscitation 2019 Sep;142:e55. [doi: 10.1016/j.resuscitation.2019.06.132]

35. Cave DM, Aufderheide TP, Beeson J, Ellison A, Gregory A, Hazinski MF, American Heart Association Emergency Cardiovascular Care Committee, Council on Cardiopulmonary, Critical Care, Perioperative and Resuscitation, Council on Cardiovascular Diseases in the Young, Council on Cardiovascular Nursing, Council on Clinical Cardiology, Advocacy Coordinating Committee. Importance and implementation of training in cardiopulmonary resuscitation and automated external defibrillation in schools: a science advisory from the American Heart Association. Circulation $2011 \mathrm{Feb}$ 15;123(6):691-706. [doi: 10.1161/CIR.0b013e31820b5328] [Medline: 21220728]

36. Böttiger BW, Van Aken H. Kids save lives--Training school children in cardiopulmonary resuscitation worldwide is now endorsed by the World Health Organization (WHO). Resuscitation 2015 Sep;94:A5-A7. [doi: 10.1016/j.resuscitation.2015.07.005] [Medline: 26209417]

37. Dillon JJ. The role of the child in adult development Internet. Journal of Adult Development 2002;9:267-275. [doi: 10.1023/A:1020286910678]

38. Bresee S, Caruso B, Sales J, Lupele J, Freeman M. 'A child is also a teacher': exploring the potential for children as change agents in the context of a school-based WASH intervention in rural Eastern Zambia. Health Educ Res 2016 Aug 19;31(4):521-534. [doi: 10.1093/her/cyw022] [Medline: 27206442]

39. Isbye DL, Rasmussen LS, Ringsted C, Lippert FK. Disseminating cardiopulmonary resuscitation training by distributing 35,000 personal manikins among school children. Circulation 2007 Sep 18;116(12):1380-1385. [doi:

10.1161/CIRCULATIONAHA.107.710616] [Medline: 17724257]

40. Böttiger BW, Semeraro F, Altemeyer K, Breckwoldt J, Kreimeier U, Rücker G, et al. KIDS SAVE LIVES: School children education in resuscitation for Europe and the world. Eur J Anaesthesiol 2017 Dec;34(12):792-796. [doi: 10.1097/EJA.0000000000000713] [Medline: 29087993]

41. Baldi E, Savastano S, Contri E, Lockey A, Conaghan P, Hulme J, et al. Mandatory cardiopulmonary resuscitation competencies for undergraduate healthcare students in Europe: A European Resuscitation Council guidance note. Eur J Anaesthesiol 2020 Oct;37(10):839-841. [doi: 10.1097/EJA.0000000000001272] [Medline: 32925434]

42. Suppan L, Herren T, Taramarcaz V, Regard S, Martin-Achard S, Zamberg I, et al. A Short Intervention Followed by an Interactive E-Learning Module to Motivate Medical Students to Enlist as First Responders: Protocol for a Prospective Implementation Study. JMIR Res Protoc 2020 Nov 06;9(11):e24664 [FREE Full text] [doi: 10.2196/24664] [Medline: 33155574]

43. Suppan M, Stuby L, Carrera E, Cottet P, Koka A, Assal F, et al. Asynchronous Distance Learning of the National Institutes of Health Stroke Scale During the COVID-19 Pandemic (E-Learning vs Video): Randomized Controlled Trial. J Med Internet Res 2021 Jan 15;23(1):e23594 [FREE Full text] [doi: 10.2196/23594] [Medline: $\underline{3428581]}$

44. Nishiyama C, Iwami T, Murakami Y, Kitamura T, Okamoto Y, Marukawa S, et al. Effectiveness of simplified 15-min refresher BLS training program: a randomized controlled trial. Resuscitation 2015 May;90:56-60. [doi: 10.1016/j.resuscitation.2015.02.015] [Medline: 25724354]

45. Niles D, Sutton R, Donoghue A, Kalsi M, Roberts K, Boyle L, et al. "Rolling Refreshers": a novel approach to maintain CPR psychomotor skill competence. Resuscitation 2009 Aug;80(8):909-912. [doi: 10.1016/j.resuscitation.2009.04.021] [Medline: 19467759 ]

46. Kovács E, Jenei ZM, Csordás K, Fritúz G, Hauser B, Gyarmathy VA, et al. The timing of testing influences skill retention after basic life support training: a prospective quasi-experimental study. BMC Med Educ 2019 Dec 04;19(1):452 [FREE Full text] [doi: 10.1186/s12909-019-1881-7] [Medline: 31801502]

47. Loxton D, Harris ML, Forder P, Powers J, Townsend N, Byles J, et al. Factors Influencing Web-Based Survey Response for a Longitudinal Cohort of Young Women Born Between 1989 and 1995. J Med Internet Res 2019 Mar 25;21(3):e11286 [FREE Full text] [doi: 10.2196/11286] [Medline: $\underline{\text { 30907739] }}$

48. Christensen T, Riis AH, Hatch EE, Wise LA, Nielsen MG, Rothman KJ, et al. Costs and Efficiency of Online and Offline Recruitment Methods: A Web-Based Cohort Study. J Med Internet Res 2017 Mar 01;19(3):e58 [FREE Full text] [doi: 10.2196/jmir.6716] [Medline: 28249833]

49. Ebert JF, Huibers L, Christensen B, Christensen MB. Paper- or Web-Based Questionnaire Invitations as a Method for Data Collection: Cross-Sectional Comparative Study of Differences in Response Rate, Completeness of Data, and Financial Cost. J Med Internet Res 2018 Jan 23;20(1):e24 [FREE Full text] [doi: 10.2196/jmir.8353] [Medline: 29362206] 
50. Ock M, Han Y, Choi EY, Pyo J, Lee W. Perceptions of Medical Students Regarding Career Counseling in Korea: A Qualitative Study. Int J Environ Res Public Health 2020 May 16;17(10):3486 [FREE Full text] [doi: 10.3390/ijerph17103486] [Medline: $\underline{\text { 32429488] }}$

51. Vaillancourt C, Stiell IG, Wells GA. Understanding and improving low bystander CPR rates: a systematic review of the literature. CJEM 2008 Jan;10(1):51-65. [doi: 10.1017/s1481803500010010] [Medline: 18226319]

\author{
Abbreviations \\ AED: automated external defibrillator \\ AGSS: Association Genevoise des Sections de Samaritains \\ BLS: basic life support \\ CPR: cardiopulmonary resuscitation \\ eLearning: electronic learning \\ OHCA: out-of-hospital cardiac arrest \\ UGFM: University of Geneva Faculty of Medicine
}

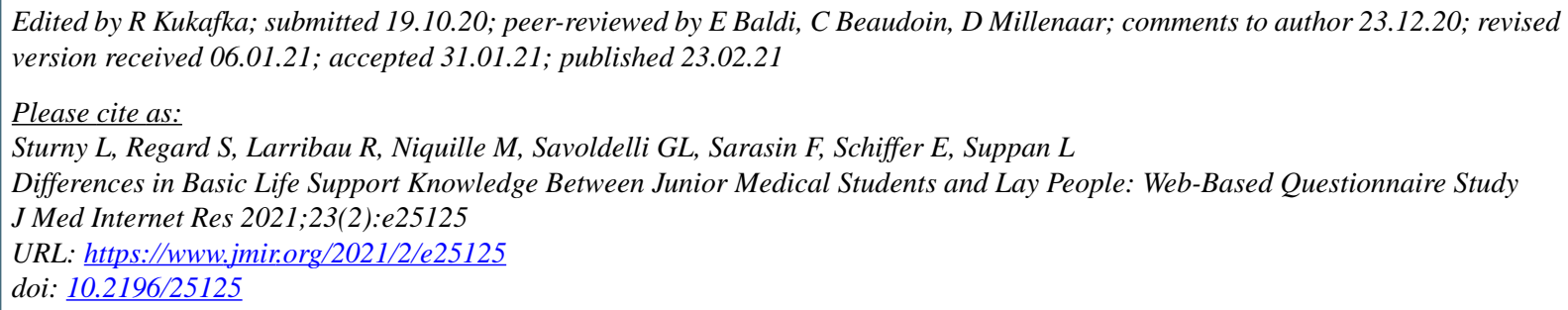

CLudovic Sturny, Simon Regard, Robert Larribau, Marc Niquille, Georges Louis Savoldelli, François Sarasin, Eduardo Schiffer, Laurent Suppan. Originally published in the Journal of Medical Internet Research (http://www.jmir.org), 23.02.2021. This is an open-access article distributed under the terms of the Creative Commons Attribution License (https://creativecommons.org/licenses/by/4.0/), which permits unrestricted use, distribution, and reproduction in any medium, provided the original work, first published in the Journal of Medical Internet Research, is properly cited. The complete bibliographic information, a link to the original publication on http://www.jmir.org/, as well as this copyright and license information must be included. 